two ranges is a factor which adds considerably to the ease of operation of the receivers so fitted. Those familiar with difficulties of tuning in short-wave stations will also appreciate the improvements in the mechanical portion of the slow-motion drive to the tuning condensers, as well as the large easily read scale which is generally provided nowadays. Several of the receivers shown at the exhibition were provided with a wave-length range in the ultra-short wave band, so that they may be used for the reception of the sound portion of the television programmes.

This year's exhibition was not so conspicuous as some of the previous ones for radical modifications in the types of valves incorporated in receivers, but two points here are worthy of note. The development of the tetrode output valve has caused the rating of most mains-operated receivers to be raised from the previous value of 2-3 watts to 5 watts or above. Secondly, one manufacturer of an all-wave supersonicheterodyne receiver is experimenting with the use of theHarries all-stage valve. In this receiver all six valves are of the same seven-electrode type, the valves being adapted for their functions in the various stages by suitable external connexion to the electrodes. It will be interesting to observe the results of this innovation, since the advantages of using the same type of valve in any position in a receiver are self-evident.

In the case of battery-operated sets, the main problem all the time is to obtain sufficient output of good quality without overloading the normal hightension battery, the size of which has now become fairly well standardized. Although the output from such receivers seldom exceeds half a watt nowadays, considerable improvement in acoustic sensitivity has been attained by the use of improved magnetic alloys for the small permanent magnet loud-speakers generally employed in such sets. There is ample evidence that the portable wireless receiver has still a wide field of service, and the attractions of several of this year's models are enhanced by the inclusion of a properly designed short-wave range.

Probably the most interesting feature of Radiolympia this year, from a technical point of view, was the fact that more than a dozen manufacturers showed fully developed television receivers suitable for the programmes now regularly provided from the London station. Direct reception of these programmes was carried out at the exhibition, and facilities were provided for each firm to give demonstrations to the public under comfortable viewing conditions. So far, little uniformity is noticeable in the design of the television receivers produced by the different manufacturers, although they naturally all employ the cathode ray tube for the reproduction of the picture image. There is a tendency to favour the use of the supersonic heterodyne receiver, although in a number of sets the amplification is carried out at the ultra-high frequency employed for the television service. There is as yet no uniformity in the methods employed for the control of the electron beam in the cathode ray tube, as both mag. netic and electric methods are employed for focusing and deflection. One of the most interesting television receivers exhibited employs a tube of only 4 inches diameter; the image produced on the fluorescent screen of this tube is projected on to an etched glass sereen giving a picture of size $20 \mathrm{in} . \times 16$ in. The more normal method, however, is to produce the final picture on the screen of the cathode ray tube and to view this either directly or through an inclined mirror. The normal size of picture for receivers priced at 60 guineas upwards is about 10 in. $\times 8$ in. ; but some cheaper receivers are now available giving a picture size of about $7 \frac{1}{2}$ in. $\times 6$ in. With the view of obtaining the utmost economy in the production of a television receiver, one type shown provides the circuits for the vision signal only, a normal broadcast receiver being required in addition to reproduce the sound accompaniment. In this way, a receiver giving a picture about 6 in. $\times 4 \frac{1}{2}$ in. in size can be obtained for about $£ 35$. This is a development likely to be worth exploring in the attempt to produce a television receiver at a price sufficiently low to appeal to a large number of listeners who already possess a normal broadcasting receiver.

In concluding this review of the exhibition organized by the Radio Manufacturers Association, mention must be made of the interesting museum provided to illustrate the evolution of the modern broadcasting receiver, and of the extension to the television field of the interesting demonstrations provided by the Post Office to illustrate the deleterious effect of various classes of electrical interference on the conditions of broadcast reception. Finally, it must not be forgotten that one of the most popular attractions of Radiolympia is the provision by the British Broad. casting Corporation of daily variety concerts in a specially constructed hall, which this year contained accommodation for an audience of more than 5,000 .

R. L. S.-R.

\title{
Isotopes of Strontium
}

$\mathrm{W}^{\circ}$ ORK on the isotopes of strontium has recently been reported by Mattauch, and by Hahn and co-workers. Mattauch (Naturwiss., 25, 170; 1937) has determined the packing fractions of the isotopes ${ }^{86} \mathrm{Sr}$ and ${ }^{87} \mathrm{Sr}$ by the doublet method, using ${ }^{29} \mathrm{SiF}_{3}$ and ${ }^{30} \mathrm{SiF}_{3}$, respectively, for comparison. Using the data of other workers for the masses of ${ }^{29} \mathrm{Si}$ and ${ }^{30} \mathrm{Si}$, the packing fraction of ${ }^{87} \mathrm{Sr}$ is found to be $-8 \cdot 7 \pm 0 \cdot 3$, and its mass $86 \cdot 924_{3} \pm 0 \cdot 004$. The packing fraction of ${ }^{86} \mathrm{Sr}$ is $-9 \cdot 0 \pm 0 \cdot 5$, and its mass $85 \cdot 922_{6} \pm 0 \cdot 004$.

The radioactive transformation of rubidium into the strontium isotope of mass 87 has been investigated by Hahn, Strassmann and Walling (Naturwiss., 25, $189 ; 1937)$, who examined the strontium occurring in a mica from Silver-leaf mine, Manitoba. The mica was comparatively rich in rubidium (containing 2-3 per cent of it), but contained only a very minute amount (a few hundredths of a per cent) of alkali earth metals. Careful treatment of the mineral resulted in the isolation of $250 \mathrm{mgm}$. of strontium carbonate. If rubidium breaks down by radioactive disintegration to give strontium, it would be expected that the product of disintegration would be present in the mineral in comparatively small amount. As alkali earth metals were actually almost entirely absent, it is very likely that the small quantity of strontium present was derived from this disintegration. The geological age of the mica is estimated at 
500-1,000 million years, whilst the half-life period of rubidium is between $2 \times 10^{11}$ and $4 \times 10^{11}$ years.

An investigation of the isotopic constitution of the strontium from the mineral throws much light on its origin. This has been carried out by Mattauch (Naturwiss., 25, 189; 1937), who finds the strontium to contain $99 \cdot 97$ per cent of the isotope of strontium of mass 87 . It is therefore very probable that the $\beta$-radioactive disintegration of ${ }^{89} \mathrm{Rb}$ results in the formation of ${ }^{87} \mathrm{Sr}$. This is in agreement with the rule that stable isobares of neighbouring elements do not exist. A rough estimate of the quantity of strontium produced during the life of the mica shows that the half-life period of radioactive rubidium is more nearly $2 \times 10^{11}$ years than the upper limit mentioned above.

\section{University Events}

CAPE Town.-Prof. A. W. Falconer has been appointed to succeed Sir Carruthers Beattie as principal and vice-chancellor of the University. Sir Carruthers Beattie will retire at the end of the year. Prof. Falconer is at present professor of medicine in the University.

Cambridge.-T. R. C. Fox, of Jesus College, and J. Diamond, of St. John's College, have been appointed demonstrators in engineering.

Dr. R. A. Lyttleton and M. H. L. Price have been appointed Faculty assistant lecturers in mathematics.

J. Hart-Mercer has been elected to the Gwynaeth Pretty studentship and to the Nita King scholarship.

At St. John's College, a Strathcona exhibition for physics has been awarded to R. E. B. Makinson, University of Sydney, and a Hutchinson studentship for zoology to J. H. Sang, University of Aberdeen.

\section{Science News a Century Ago}

\section{J. D. Forbes among the Dolomites}

IN the course of his Continental tour of 1837 , J. D. Forbes after leaving southern Germany explored the Tyrol and early in September entered the then little-known 'Dolomite' country, proceeding in the direction of the peak of Marmolata. In his journal, under the date September 14, he said: "This morning, whilst warming myself dreamily during the rain at the kitchen fire at Cavalese, I got an excellent geological lesson from the boiling of certain thin porridge made of Indian corn (polenta) and milk. The air-bubbles disengaged during the process formed the most beautiful elevation craters, often with little interior ones, formed by the immediate sequence of another bubble at the same point. ... I walked from Cavalese to Vigo, in order to understand fully Von Buch's section of the adjacent beds of rock, and in this I succeeded beyond my expectations. But the strata of limestone and sand. stone do not all dip towards the axis, as he has represented, but some from it, and with evident disturbance. I went in search of minerals to a dealer's, but only found some very indifferent specimens.

"The scenery from Vigo to Campedello, and from that to Canazea, is in the highest degree strikingin fact, I know nothing of its kind to compare with it : one is entirely surrounded by jagged peaks of dolomite. The amazing crags of the Lang Kofel come into view near Campedello, and afterwards the magnificent outworks of the Marmolata and Sasso di Val Fredda are seen in all their majestic beauty. As I wished to examine the Lang Kofel more minutely, as well as Von Buch's sections between Gröden and Colfusco in the Abteier-Thal, I availed myself of a tolerable horse track which wound through the forest, and after passing close under the precipices of the Lang Kofel, entered the Grödener-Thal. . . ."

\section{Prof. William Ritchie, F.R.S.}

ON September 15, 1837, William Ritchie, the professor of natural philosophy at the Royal Institution and also in University College, London, died at the age of forty-seven years. Born in Scotland in 1790, he was educated for the ministry and became Rector of the Royal Academy of Tain, Ross-shire. Having saved money he went to Paris, where he attended the lectures of Thénard, Gay-Lussac and Biot and on his return to England became known to Sir John Herschel. Papers he contributed to the Royal Society on a differential thermometer and radiant heat brought him into notice, and in 1829 he was given the professorship at the Royal Institution and in 1832 that at University College. He published papers in the Philosophical Magazine and other periodicals and made researches in electricity and electric magnetism. He was also known as a skilful experimentalist, and at one time was engaged on experiments connected with the manufacture of glass for optical purposes.

\section{Animal Magnetism}

The Gentleman's Magazine of September 1837 gives the following information: "At the North London Hospital, M. Duportet, the French professor of animal magnetism, lately performed some experiments before a party. He commenced his operations on a young girl, about 17 years old, an inmate of the hospital, who has been ill for some time, but who is at present almost convalescent. She was seated in a chair in the middle of one of the wards, and M. Duportet seated opposite to her commenced the operation of magnetizing, which is done by waving the hand up and down in a perpendicular line before the face and body, as closely as possible without almost actual contact. After these motions of the hand had been continued for some minutes without effect, the professor, nothing disconcerted, left off, and another patient was introduced, who, we understood, had been operated upon more than once, deriving, it is stated, some benefit in her health. She was a young woman named Lucy Clarke, who having for some time past been subject to epileptic fits, had been induced to come to the hospital from Tottenham, where she resided, that the experiment might be made upon her. As soon as she was seated Prof. Duportet commenced the wafting of his hands, and in a few seconds an appearance of extreme drowsiness became evident to all who stood around his chair, and she frequently rubbed her eyes as children do when sleepy. She at length ceased to have the power of opening her eyes. The magnetizer, however, who had placed her under the spell, had the power also of restoring her to a state of wakefulness. This he did by placing his fingers on the centre of the forehead and drawing them asunder towards the temples, and afterwards waving the hand to and fro before her face." 